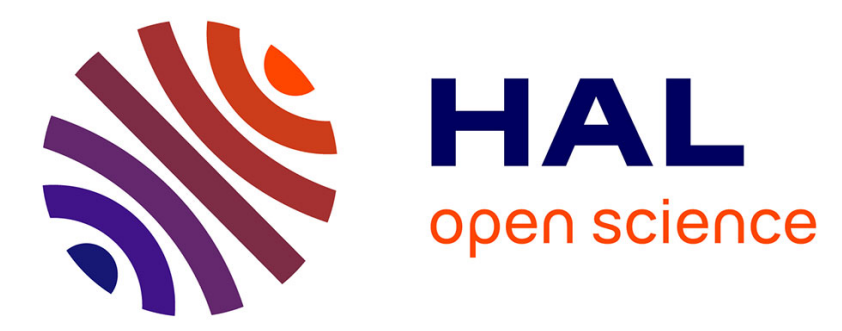

\title{
Remanent magnetization and anisotropic susceptibility in the spin-glass phase of amorphous PbMnFeF7
}

\author{
E. Velu, J.P. Renard, J.P. Miranday
}

\section{To cite this version:}

E. Velu, J.P. Renard, J.P. Miranday. Remanent magnetization and anisotropic susceptibility in the spin-glass phase of amorphous PbMnFeF7. Journal de Physique Lettres, 1981, 42 (11), pp.237-240. 10.1051/jphyslet:019810042011023700 . jpa-00231917

\section{HAL Id: jpa-00231917 https://hal.science/jpa-00231917}

Submitted on 1 Jan 1981

HAL is a multi-disciplinary open access archive for the deposit and dissemination of scientific research documents, whether they are published or not. The documents may come from teaching and research institutions in France or abroad, or from public or private research centers.
L'archive ouverte pluridisciplinaire HAL, est destinée au dépôt et à la diffusion de documents scientifiques de niveau recherche, publiés ou non, émanant des établissements d'enseignement et de recherche français ou étrangers, des laboratoires publics ou privés. 


\title{
Remanent magnetization and anisotropic susceptibility in the spin-glass phase of amorphous $\mathrm{PbMnFeF}_{7}$
}

\author{
E. Velu, J.P. Renard \\ Institut d'Electronique Fondamentale, Bât. 220, 91405 Orsay, France
}

and J. P. Miranday (†)

Laboratoire des fluorures et oxyfluorures ioniques $\left({ }^{*}\right)$, Université du Maine, Route de Laval, 72017 Le Mans Cedex, France

(Reçu le 12 mars 1981, accepté le 8 avril 1981)

\begin{abstract}
Résumé. - Nous avons mesuré les aimantations isotherme rémanente et thermorémanente du verre de spin amorphe $\mathrm{PbMnFeF}_{7}$. Nous avons ensuite mesuré les susceptibilités parallèle $\chi_{\|}$et perpendiculaire $\chi_{\perp}$ à l'aimantation rémanente $\sigma$. On observe que $\chi_{\perp}>\chi_{\|}$. Cette anisotropie peut s'expliquer par un modèle simple de champ d'anisotropie macroscopique $H_{\mathrm{A}}$. $H_{\mathrm{A}}$ dépend de $\sigma$ et non de la température ou de l'histoire magnétique de l'échantillon à la précision des expériences près.
\end{abstract}

\begin{abstract}
Isothermal remanent and thermoremanent magnetizations were measured in the spin-glass phase of amorphous $\mathrm{PbMnFeF}_{7}$. After creating a remanent magnetization $\sigma$, the susceptibilities parallel to $\sigma, \chi_{\|}$, and perpendicular to $\sigma, \chi_{\perp}$, were measured. It is observed that $\chi_{\perp}>\chi_{\|}$. This anisotropy can be explained by a simple model of a macroscopic anisotropy field $H_{\mathrm{A}} . H_{\mathrm{A}}$ seems to depend on $\sigma$ and not on the temperature or on the magnetothermal history of the sample.
\end{abstract}

Several NMR and ESR experiments in CuMn [1] have shown that this spin-glass could not be considered as an assembly of independent clouds with random magnetizations fixed by random anisotropy fields. Recently $\mathrm{H}$. Alloul and F. Hippert [2] have proved in CuMn that, once a remanent magnetization $\sigma$ has been established, a macroscopic anisotropy field appears parallel to the field $\mathbf{H}_{c}$ which has created $\sigma$.

According to a phenomenological representation of this anisotropy similar to that of a ferrimagnetic system, the energy of the spin-glass can be written :

$$
E=E_{\text {iso }}+K \sin ^{2} \psi
$$

where $E_{\text {iso }}$ is the energy in the absence of remanent magnetization and $\psi=(\sigma, \mathbf{z})$ where $\mathbf{z}$ is the direction of $\mathbf{H}_{\mathrm{c}}$. A small field $\mathbf{h}$ is applied to measure the susceptibility. If $\mathbf{h}$ is parallel to $\mathbf{z}, \psi=0$ and $\chi_{\|}=\chi_{\text {iso. }}$. If $h$ is perpendicular to $z$, it induces a collective rotation of the magnetization and $\psi=h / H_{\mathrm{A}}$ where $H_{\mathrm{A}}$ is the anisotropy field parallel to $\mathrm{z}$ and equal to $2 K / \sigma$.

(*) ERA 609
The transverse susceptibility is given by :

or

$$
\chi_{\perp}=\chi_{\text {iso }}+\frac{\sigma}{H_{\mathrm{A}}}
$$

$$
\Delta \chi_{\sigma_{\perp}} \chi_{\perp}-\chi_{\|}=\frac{\sigma}{H_{\mathrm{A}}}=\frac{\sigma^{2}}{2 K} .
$$

We have checked this relation in the amorphous insulating spin-glass $\mathrm{PbMnFeF}_{7}$ and we have studied how the coefficient $K$ depends on the magnetothermal history of the sample.

In a previous paper [3], we showed that $\mathrm{PbMnFeF}_{7}$ displays a spin-glass phase below the freezing temperature $T_{\mathrm{f}}=11.77 \mathrm{~K}$. In this work we present some measurements of alternative susceptibility in zero field and some measurements of thermoremanent magnetization (TRM) and isothermal remanent magnetization (IRM) versus the temperature $T$ $(1.2<T<4.2 \mathrm{~K})$, the field $H_{\mathrm{c}}\left(0.125 \mathrm{~T}<H_{\mathrm{c}}<4 \mathrm{~T}\right)$ and the time $t$.

1. Remanent magnetizations. - The magnetic field $H_{\mathrm{c}}$ which creates the remanent magnetization is 
applied in all the experiments except one, by a supraconducting coil with a high self $(5 \mathrm{H})$. The field cannot be switched off suddenly. The highest variation rate used here is $0.25 \mathrm{~T} / \mathrm{min}$. The remanent magnetization is measured in zero field by a fluxmetric method.

The TRM is obtained by cooling the sample below $T_{\mathrm{f}}$ in presence of the field $H_{\mathrm{c}}$. At $T \ll T_{\mathrm{f}}$, the field is switched off and $\sigma$ is measured at a fixed temperature, first every $2 \mathrm{~min}$. for $20 \mathrm{~min}$., then every $5 \mathrm{~min}$. until about $1 \mathrm{~h}$ after switching off the field (Fig. 1b). In one case, with a smaller coil

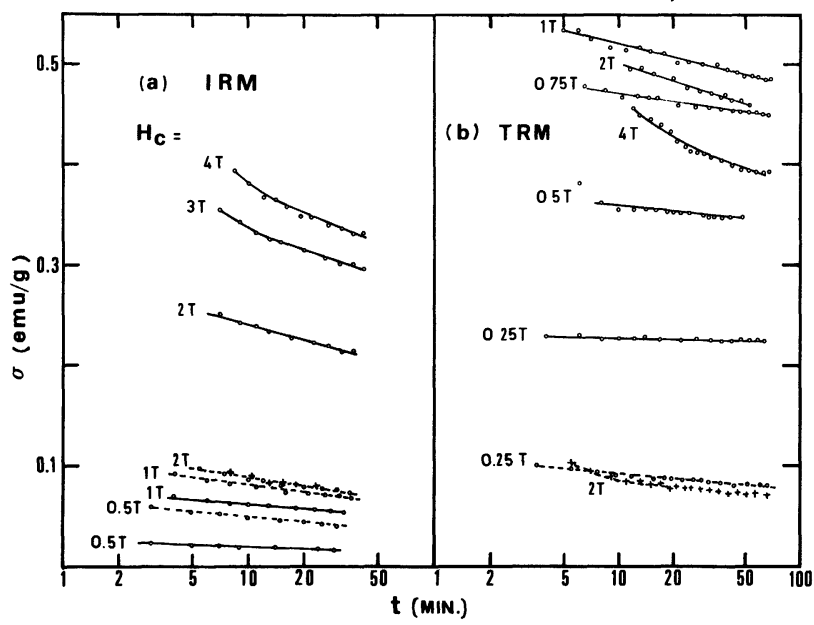

Fig. 1. - Time dependence of the remanent magnetization $\sigma$ in $\mathrm{PbMnFeF}_{7}$ for several values of the field $H_{\mathrm{c}} \cdot t=0$ is the time when $H=H_{\mathrm{c}} / 2$ during the field decrease. Heavy lines correspond to $T=1.24 \mathrm{~K}$, dashed lines to $T=4.2 \mathrm{~K}$. (a) Isothermal remanent magnetization. $+: H_{c}=3 \mathrm{~T}$. (b) Thermoremanent magnetization.

which allows one to switch off the field suddenly, the TRM is measured at $4.2 \mathrm{~K}$ with $H_{\mathrm{c}}=0.125 \mathrm{~T}$ from $1 \mathrm{~s}$ to $21 \mathrm{~h}$ (Fig. 2).

The IRM is obtained by cooling down to $T \ll T_{\mathrm{f}}$ in zero field and then the field $H_{\mathrm{c}}$ is applied for $30 \mathrm{~min}$. Measurements are made first every $2 \mathrm{~min}$. and afterwards every $5 \mathrm{~min}$. until $30 \mathrm{~min}$. after switching off the field (Fig. 1a).

It is observed that for $5<t<60 \mathrm{~min}$. and

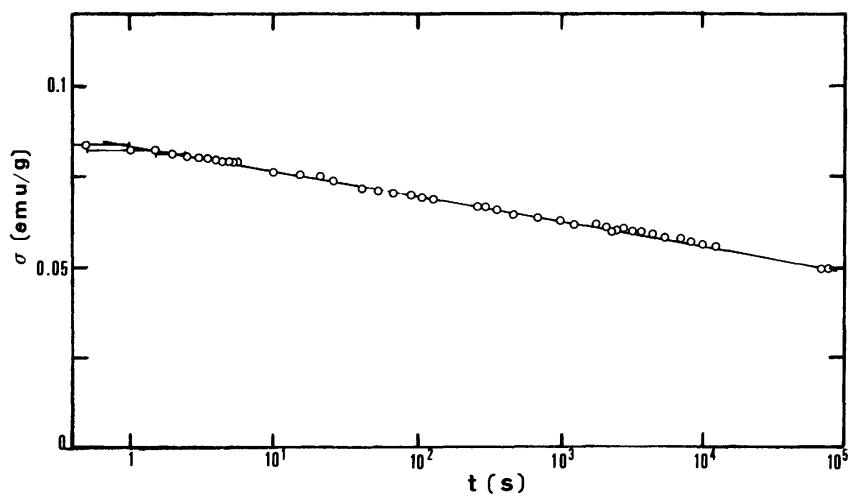

Fig. 2. - Time dependence of the TRM built at $4.2 \mathrm{~K}$ and in $H_{\mathrm{c}}=0.125 \mathrm{~T} . \sigma$ is a linear function of $\log t$.
$H_{\mathrm{c}}<2 \mathrm{~T}$, the time dependence or relaxation of the remanent magnetization can be fitted by the law

$$
\sigma\left(t, T, H_{\mathrm{c}}\right)=\sigma\left(t_{0}, T, H_{\mathrm{c}}\right)-B\left(T, H_{\mathrm{c}}\right) \log \frac{t}{t_{0}} .
$$

In the special case of the TRM at $4.2 \mathrm{~K}$ and for $H_{\mathrm{c}}=0.125 \mathrm{~T}$, the law (2) holds from $1 \mathrm{~s}$ to $76400 \mathrm{~s}$ (Fig. 2).

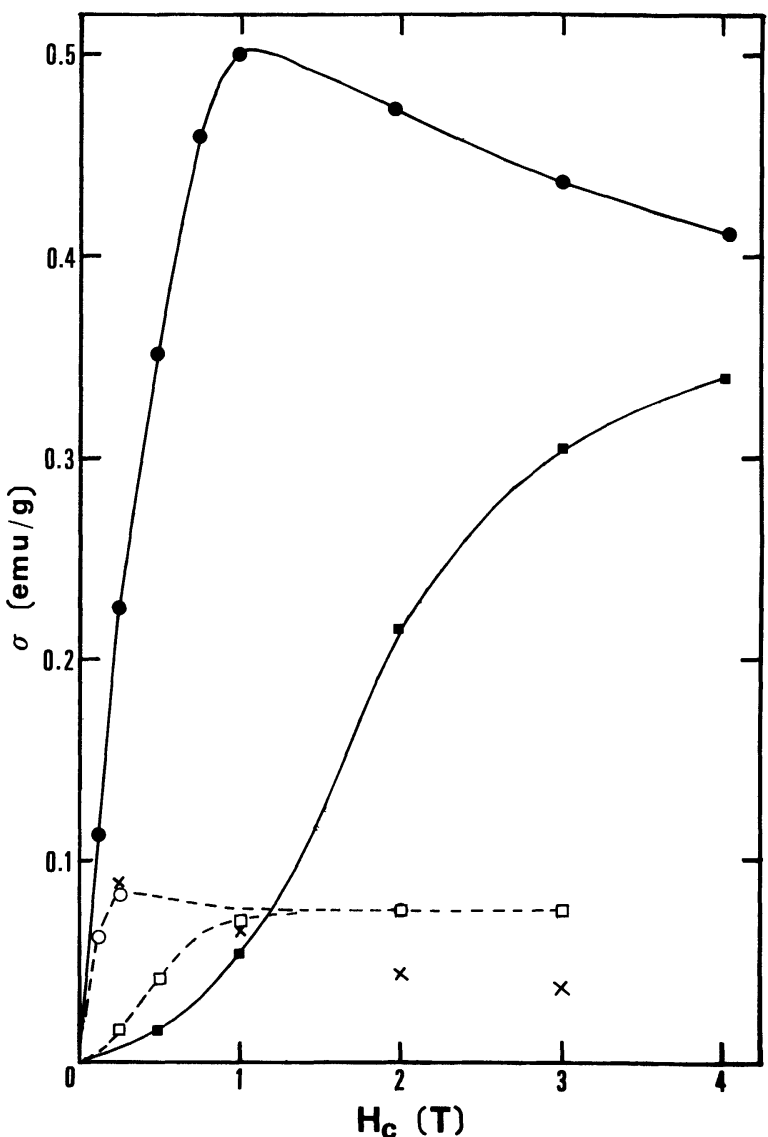

Fig. 3. $-\sigma\left(t_{0}, T, H_{\mathrm{c}}\right)$ versus $H_{\mathrm{c}}$ with $t_{0}=30 \mathrm{~min}$. TRM at $1.24 \mathrm{~K}$, O TRM at $4.2 \mathrm{~K}$, $\square$ IRM at $1.24 \mathrm{~K}, \square$ IRM at $4.2 \mathrm{~K}$, $x$ the residue at $4.2 \mathrm{~K}$ of the TRM obtained at $1.24 \mathrm{~K}$.

In figure 3 , the curves $\sigma\left(t_{0}, T, H_{\mathrm{c}}\right)$ versus $H_{\mathrm{c}}$ are plotted for $t_{0}=30 \mathrm{~min}$. and for $T=1.24 \mathrm{~K}$ and $4.2 \mathrm{~K}$. These curves are rather similar to the ones obtained in the previously studied spin-glasses [4]. Particularly the TRM is higher than the IRM for fields lower than the saturation field $H_{\mathrm{s}}$ (here, $H_{\mathrm{s}}>5 \mathrm{~T}$ for $T=1.24 \mathrm{~K}$ and $H_{\mathrm{s}} \simeq 1.5 \mathrm{~T}$ for $T=4.2 \mathrm{~K}$ ) and it displays a very clear maximum. Rajchenbach [5] has shown recently that this maximum could be explained by the relaxation variation with $H_{\mathrm{c}}$. Indeed, figure 1 shows that, at fixed temperature, the relaxation rate increases when the field increases. Two opposite effects pperate on $\sigma: \sigma$ increases when $H_{\mathrm{c}}$ increases but the rate of decrease of $\sigma$ increases when $H_{\mathrm{c}}$ increases. The result of this is that the shape of the curves $\sigma\left(t_{0}, T, H_{\mathrm{c}}\right)$ versus $H_{\mathrm{c}}$ depends on $t_{0}$. Particularly the TRM maximum is shifted towards the higher fields if $t_{0}$ decreases. 
Another effect can be explained by the relaxation increase with $H_{\mathrm{c}}$. The TRM is built at $T=1.24 \mathrm{~K}$. Then, in zero field, the temperature is increased step by step until $4.2 \mathrm{~K}$. Every temperature step lasts about $15 \mathrm{~min}$. The residue of $\sigma$ is measured as a temperature function. $\sigma(T)$ is plotted for several

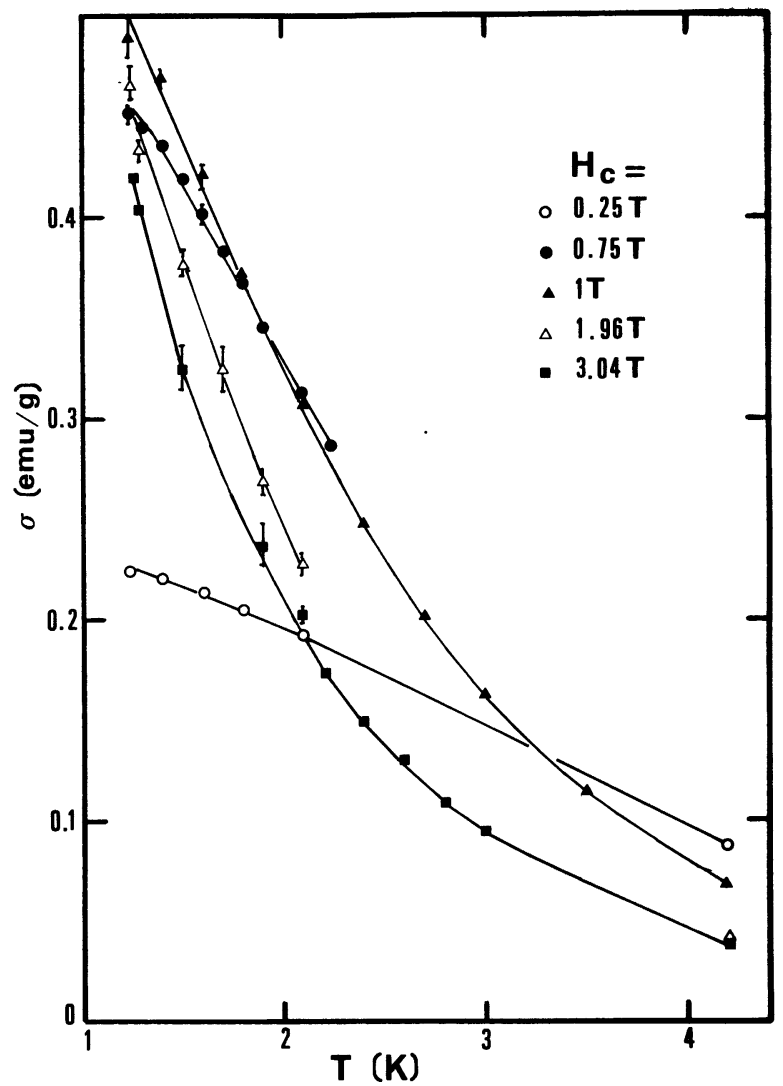

Fig. 4. - Temperature dependence for several values of $H_{\mathrm{c}}$ of the residue of the TRM built in $H_{\mathrm{c}}$ at $T=1.24 \mathrm{~K}$. The temperature is afterwards increased step by step.

$H_{\mathrm{c}}$ values in figure 4 . It is observed that the higher the field $H_{\mathrm{c}}$, the faster the $\sigma$ decrease with $T$ so much so that the residue of the TRM built in $0.25 \mathrm{~T}$ is larger than the one built in 1 and $3 \mathrm{~T}$. In figure 3 the TRM residue at $4.2 \mathrm{~K}$ can be compared with the true TRM at $4.2 \mathrm{~K}$ measured at the same time after switching off the field.

2. Susceptibilities. - The susceptibility $\chi$ is measured by a mutual inductance bridge at $75 \mathrm{~Hz}$. The sample in form of flakes is put in a cylindrical box attached to a pulley which is rotated by a cotton wire. This system allows the sample to be rotated around a horizontal axis and the susceptibility to be measured along all the directions perpendicular to the rotation axis. A remanent magnetization is built in $\mathrm{PbMnFeF}_{7}$. Then $\chi$ is measured along a direction at the angle $\theta$ with the field $H_{\mathrm{c}} \cdot \chi(\theta)$ is a sinusoidal function with the period $\pi$, minimum for $\theta=0\left(\chi_{\|}\right)$and maximum for $\theta=\frac{\pi}{2}\left(\chi_{\perp}\right)$. The dif- ference $\Delta \chi=\chi_{\perp}-\chi_{\|}$is measured in the following conditions :

- In presence of the TRM at $1.24 \mathrm{~K}$ and $H_{\mathrm{c}}=1 \mathrm{~T}$ and then heating the sample step by step until $4.2 \mathrm{~K}$.

- In presence of the TRM at $1.24 \mathrm{~K}$ and $H_{\mathrm{c}}=3 \mathrm{~T}$ and then heating until $4.2 \mathrm{~K}$.

- In presence of the IRM at $1.24 \mathrm{~K}$ and $H_{\mathrm{c}}=2 \mathrm{~T}$.

- In presence of the IRM at $1.24 \mathrm{~K}$ and $H_{\mathrm{c}}=4 \mathrm{~T}$.

In the experiments involving heating of the TRM, the difficulty is to get the same timing as in the $\sigma$ measurements. In figure $5 \Delta \chi$ is plotted versus $\sigma$.

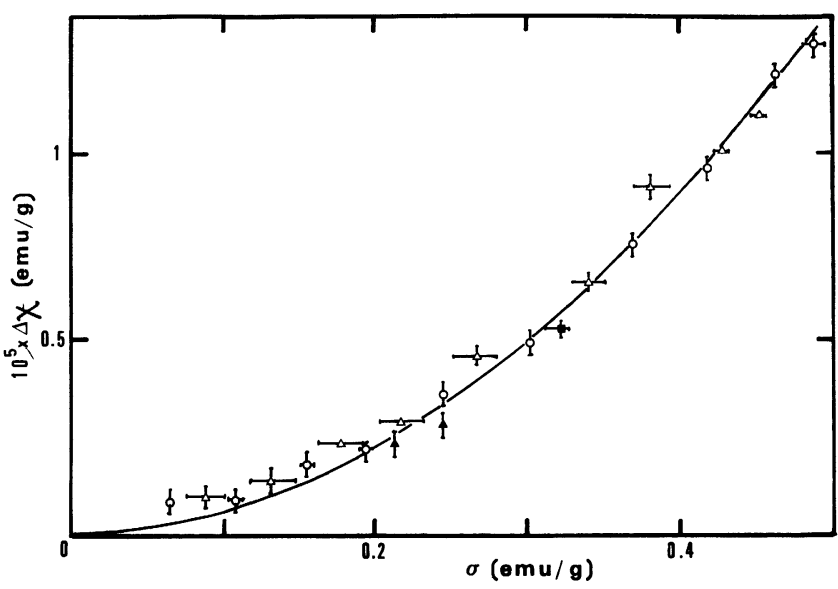

Fig. 5. $-\Delta \chi$ versus $\sigma . \sigma$ is : $O$ the residue of the TRM built at $1.24 \mathrm{~K}$ in $H_{\mathrm{c}}=1 \mathrm{~T}, \Delta$ the residue of the TRM built at $1.24 \mathrm{~K}$ in $H_{\mathrm{c}}=3 \mathrm{~T}, \Delta$ the IRM at $1.24 \mathrm{~K}$ in $H_{\mathrm{c}}=2 \mathrm{~T}$, the IRM at $1.24 \mathrm{~K}$ in $H_{\mathrm{c}}=4 \mathrm{~T}$. The heavy line is $\Delta \chi=\sigma / 2 K$ with $K=8900 \mathrm{erg} \cdot \mathrm{g}^{-1}$.

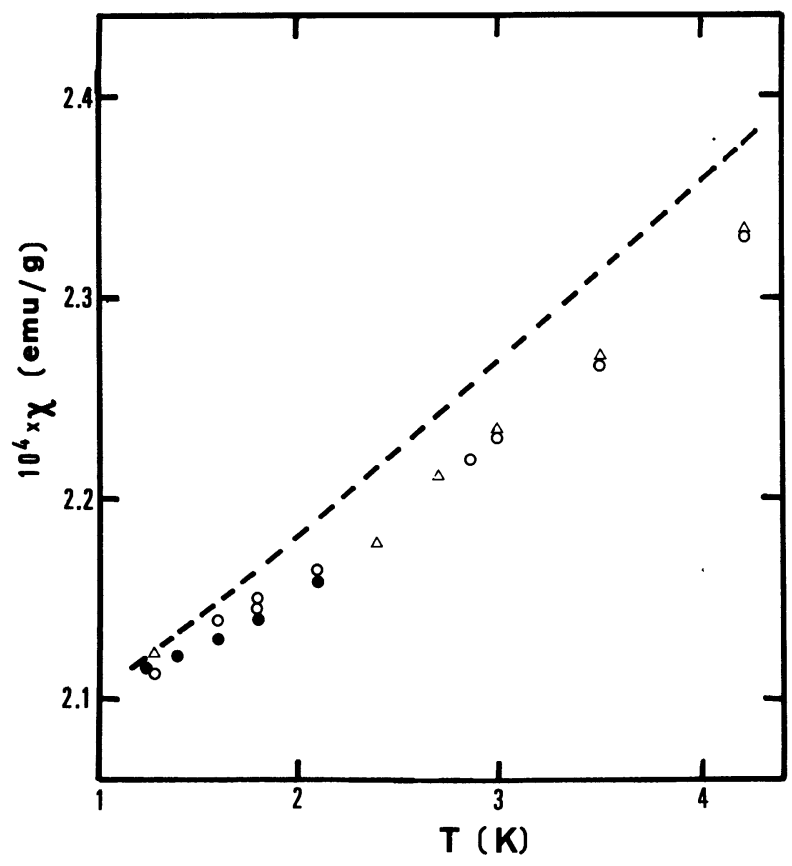

Fig. 6. - Comparison of $\chi_{\text {iso }}$ (dashed line) with $\chi_{\|}$(dots) in presence of a remanent magnetization $\sigma . O: \sigma$ is the residue of the TRM built at $1.24 \mathrm{~K}$ in $H_{\mathrm{c}}=1 \mathrm{~T}$. $\bullet: \sigma$ is the residue of the IRM built at $1.24 \mathrm{~K}$ in $H_{\mathrm{c}}=4 \mathrm{~T}$. $\Delta: \sigma$ is the TRM created by $H_{\mathrm{c}}=1 \mathrm{~T}$ at several temperatures following the method exposed in the text. 
The experimental data appear to be distributed along a unique curve in accordance with expression (1) taking $K=8900 \mathrm{erg} / \mathrm{g}$. In the studied range the susceptibility anisotropy does not depend on the magnetothermal history of the sample but only on the remanent magnetization. Our experiments are well described by the simple model of an anisotropy field and they give evidence for the existence of a macroscopic rotation of the remanent magnetization in an external field.

Finally in figure 6, we have also compared the susceptibility measured without remanent magnetization $\chi_{\text {iso }}$ with $\chi_{\|}$measured in presence of remanent magnetization obtained by the following methods :

- IRM at $1.24 \mathrm{~K}$ and $4 \mathrm{~T}$ and after heating.

- TRM at $1.24 \mathrm{~K}$ and $1 \mathrm{~T}$ and after heating.

- TRM built in $H_{\mathrm{c}}=1 \mathrm{~T}$ at several temperatures by the following method :

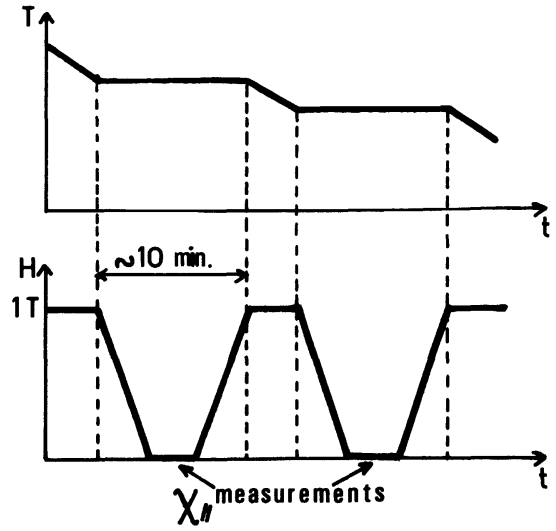

Fig. 7.

$\chi_{\|}$is observed to be lower than $\chi_{\text {iso }}$. The difference $\chi_{\text {iso }}-\chi_{\|}$increases with temperature

$$
\left(\frac{\chi_{\text {iso }}-\chi_{\|}}{\chi_{\text {iso }}} \simeq 0.02 \text { at } T=4.2 \mathrm{~K}\right) \text {. }
$$

At the moment, no satisfactory explanation can be found for this phenomenon.

\section{References}

[1] Alloul, H., MMM Conference, J. Appl. Phys. 50 (1979) 7330. Monod, P. and BerthIER, Y., ICM 79, J. Mag. Mag. Mat. 15-18 (1980) 149.

See also : Prejean, J. J., Joliclerc, M. J., Monod, P., $J$. Physique 41 (1980) 427.

[2] Alloul, H. and Hippert, F., J. Physique Lett. 41 (1980) L-201.

[3] Renard, J. P., Miranday, J. P. and Varret, F., Solid State Commun. 35 (1980) 41.
[4] For example :

ThOlence, J. L., Tournier, R., J. Physique Colloq. 35 (1974) C 4-229.

Maletta, H. and Felsch, W., Phys. Rev. B 20 (1979) 1245. Ferré, J., Pommier, J., Renard, J. P. and Knorr, K., J. Phys. C 13 (1980) 3697.

[5] Ferré, J., Rajchenbach, J. and Maletta, H., MMM Conference, Dallas (1980), to be published. 